\title{
Early childhood growth is associated with lung function at seven years: a prospective population-based study
}

Gabriela P. Peralta ${ }^{1,2,3}$, Alicia Abellan ${ }^{1,2,3,4}$, Parisa Montazeri ${ }^{1,2,3}$, Mikel Basterrechea ${ }^{3,5}$, Ana Esplugues $^{3,6,7}$, Sandra González-Palacios ${ }^{3,8}$, Célina Roda ${ }^{1,2,3,9}$, Loreto Santa-Marina ${ }^{3,5}$, Jordi Sunyer $^{1,2,3,10}$, Martine Vrijheid ${ }^{1,2,3}$, Maribel Casas ${ }^{1,2,3 *}$, Judith Garcia-Aymerich ${ }^{1,2,3 *}$

*Shared last authorship

${ }^{1}$ ISGlobal, Barcelona, Spain

${ }^{2}$ Universitat Pompeu Fabra (UPF), Barcelona, Spain

${ }^{3}$ CIBER Epidemiología y Salud Pública (CIBERESP)

${ }^{4}$ Fundació Institut Universitari per a la recerca a l'Atenció Primària de Salut Jordi Gol i Gurina (IDIAPJGol), Barcelona, Spain

${ }^{5}$ Public Health Division of Gipuzkoa, Basque Government, San Sebastian, Spain

${ }^{6}$ Epidemiology and Environmental Health Joint Research Unit, FISABIO-Universitat Jaume I, Universitat de Valencia, Valencia, Spain

${ }^{7}$ Nursing Department, Faculty of Nursing and Chiropody, Universitat de València, Valencia, Spain

${ }^{8}$ Department of Public Health, History of Medicine and Gynecology, Miguel Hernández University and Institute for Health and Biomedical Research (ISABIAL Foundation), Alicante, Spain

${ }^{9}$ Université de Paris, CRESS, INSERM - HERA team (Health Environmental Risk Assessment), INRA, F-75004, Paris, France

${ }^{10}$ IMIM (Hospital del Mar Medical Research Institute), Barcelona, Spain

\section{Corresponding author:}

Judith Garcia-Aymerich

Barcelona Institute for Global Health (ISGlobal)

Doctor Aiguader, 88

08003 Barcelona, Spain

Email address: judith.garcia@ isglobal.org 
"Take home" message: Independently of birth size, children with accelerated BMI gain in early childhood had higher lung function at 7 years, but showed airflow limitation. Children with lower birth size and slower BMI gain in early childhood had lower lung function at 7 years. 


\begin{abstract}
Previous studies have related early postnatal growth with later lung function but their interpretation is limited by the methods used to assess child's growth. We aimed to assess the association of early childhood growth, measured by body mass index (BMI) trajectories up to four years, with lung function at seven years.

We included 1,257 children from the Spanish Infancia y Medio Ambiente population-based birth cohort. Early childhood growth was classified in five categories based on BMI trajectories up to four years previously identified using latent class growth analysis. These trajectories differed in birth size ('lower', 'average', 'higher') and in BMI gain velocity ('slower', 'accelerated'). We related these trajectories with lung function (forced expiratory volume in one second $\left(\mathrm{FEV}_{1}\right)$, forced vital capacity (FVC), $\mathrm{FEV}_{1} / \mathrm{FVC}$ and forced expiratory flow at $\left.25-75 \%\left(\mathrm{FEF}_{25-75}\right)\right)$ at seven years, using multivariable mixed regression.

Compared to children with average birth size and slower BMI gain (reference), children with higher birth size and accelerated BMI gain had higher percent predicted FVC (3.3\% [95\% CI: $1.0 ; 5.6])$ and lower percent predicted $\mathrm{FEV}_{1} / \mathrm{FVC}(-1.5 \%[-2.9 ;-0.1])$ at seven years. Similar associations were observed for children with lower birth size and accelerated BMI gain. Children with lower birth size and slower BMI gain had lower percent predicted FVC at seven years. No association was found for $\mathrm{FEF}_{25-75}$.

Independently of birth size, children with accelerated BMI gain in early childhood had higher lung function at seven years but showed airflow limitation. Children with lower birth size and slower BMI gain in early childhood had lower lung function at seven years.
\end{abstract}

\title{
Abstract word count: 258/250
}

Keywords: children, epidemiology, INMA, lung function, postnatal growth

Total word count: 3,079 


\section{BACKGROUND}

Early childhood is a critical period for lung function growth [1-3]. The respiratory system starts to develop in utero but the airways, particularly the alveoli, continue to develop until early adulthood $[1,3,4]$. Therefore, early life events can affect normal lung growth and increase the risk of respiratory morbidity in later life [5]. In recent years, several studies have assessed the association between early growth characteristics and lung function in childhood. There is consistent evidence showing that low birth weight is associated with poor lung function (mostly measured by means of forced vital capacity (FVC) and forced expiratory volume in 1 second $\left.\left(\mathrm{FEV}_{1}\right)\right)$ in childhood [6-11]. In addition, previous studies suggested that accelerated weight gain during infancy and childhood is associated with higher $\mathrm{FEV}_{1}$ and FVC levels but lower $\mathrm{FEV}_{1} / \mathrm{FVC}$ ratio, i.e., higher risk of airflow limitation [10-13].

These previous studies are limited by the methods used to assess child's growth. First, some studies calculated the differences between only two time points [6,11]. This approach can only estimate linear growth and does not fully capture growth in early childhood. Second, other studies derived complex growth patterns such as peak height and weight growth velocity [13]. Although these patterns are biologically meaningful, they are also difficult to interpret and apply in clinical settings. Other analytical strategies that integrate repeated weight information and are, at the same time, easy to interpret for paediatricians and the general public, have not yet been tested in relation to lung function.

In the present study we aimed to assess the association of body mass index (BMI) trajectories from birth to four years with lung function at seven years using data from the population-based INfancia y Medio Ambiente (INMA, "Environment and Childhood") birth cohort in Spain. We previously identified BMI z-score trajectories from birth to four years based on repeated measures of weight and height during early childhood from routine paediatric charts [14], which allow for an accurate assessment of early childhood growth and easier interpretation.

\section{METHODS}

\section{Study population}

Pregnant women $(n=2,270)$ were recruited at prenatal visits at public health care centres or referral hospitals, from 2004 to 2008, in three regions (Sabadell, Valencia and Gipuzkoa) participating in the Spanish INMA birth cohort [15]. Inclusion criteria were: $\geq 16$ years of age, singleton pregnancy, intention to deliver at reference hospital, and no assisted conception or communication issues. In the present study, we included children who had available information for the 
identification of BMI z-score trajectories from birth to four years and lung function data at seven years (Figure S1).

The study was approved by the hospital and institutional Ethics Committees in each region. All mothers signed a written consent for themselves and their child's participation.

\section{BMI z-score trajectories}

Repeated measurements of child height and weight from birth until four years were extracted from routine paediatric charts (mean [SD] number of measurements per child 11 [3.4]). We calculated BMI by dividing weight in kilograms by height squared in centimetres, and age and sex specific BMI z-scores by using the WHO Child Growth Standards [16]. We previously identified five BMI z-score trajectories (hereon referred to as BMI trajectories) using latent class growth analysis $[14,17]$. These trajectories differed in birth size (labelled for comparison as 'lower', 'average' or 'higher') and in BMI gain velocity (labelled as 'slower' or 'accelerated') (Figure 1). We used the trajectory with average birth size and slower BMI gain as the reference category in our analysis. The distribution of weight and length/height according to the BMI trajectories in our study sample is presented in Table $\mathrm{S} 1$.

\section{Lung function}

At seven years, trained nurses measured lung function by spirometry according to American Thoracic Society and the European Respiratory Society guidelines [18]. FVC, FEV 1 and forced expiratory flow at $25-75 \%$ of the $\mathrm{FVC}\left(\mathrm{FEF}_{25-75}\right)$ were measured, and the $\mathrm{FEV} / \mathrm{FVC}$ ratio was calculated. All children included in the present study had at least one acceptable manoeuvre. We calculated percent predicted lung function parameters by using the Global Lung Function Initiative 2012 prediction equations [19], and we used these variables as the main outcome of the analysis.

\section{Other relevant characteristics}

We obtained the following additional information: maternal characteristics (age at delivery, prepregnancy BMI, smoking status, educational level and history of allergy-related disease [at least one of the following: allergic asthma, atopic dermatitis, eczema or allergic rhinitis]) using questionnaires during pregnancy; child birth characteristics (sex, gestational age and weight at birth) from medical records; child characteristics (duration of any breastfeeding and lower respiratory tract infections) during the first year by postnatal questionnaires; height at seven years by trained nurses; and asthma at seven years through the International Study of Asthma and Allergies in Childhood (ISAAC) questionnaire completed by parents. As previously agreed in the MeDALL (Mechanisms of the Development of Allergy) project [20], we defined current asthma based on a positive answer to at least two of the following questions: life-time doctor diagnosis 
of asthma, use of medicines for asthma or breathing difficulties in the last 12 months, and wheezing or whistling in the chest at any time in the last 12 months (see full questions in the online supplement).

\section{Statistical analysis}

We assessed the association of BMI trajectories from birth to four years with lung function (FVC, $\mathrm{FEV}_{1}, \mathrm{FEV}_{1} / \mathrm{FVC}$ and $\mathrm{FEF}_{25-75}$ ) at seven years using multivariable mixed linear regression models with random intercepts for participants nested within regions (Sabadell, Valencia and Gipuzkoa). All models were adjusted for maternal age at delivery, pre-pregnancy BMI, history of allergyrelated disease, educational level, smoking during pregnancy, and child's gestational age, duration of any breastfeeding and lower respiratory tract infections during the first year. We selected covariates based on previous research [10-13] and on subject matter knowledge. We used Direct Acyclic Graphs to identify the minimum set of covariables required to adjust our models (Figure S2).

To assess whether associations differed by sex, we tested for interaction and stratified models by this variable. Specifically, we tested the overall significance of the interaction term using a Wald test, which tested whether interaction terms between each one of the BMI trajectories and sex were collectively different from zero and provided a single p-value for the interaction. We performed several sensitivity analyses to assess the robustness of results to various assumptions regarding inclusion of susceptible subgroups (e.g. children born prematurely or with current asthma) and quality of lung function measures (see the online supplement).

Missing data accounted for $4.9 \%$ of total observations. We used a complete case strategy and reported missing data in the Table 1 footnotes. All analyses were conducted in Stata/SE 14.0 (StataCorp, College Station, TX, USA). Statistical significance was set at $\mathrm{p}$-value $<0.05$ for multivariate analyses, and at $p$-value $<0.2$ for interaction tests.

\section{RESULTS}

\section{Sample description}

We included 1,257 children in the present analysis. Mothers of these children were older at pregnancy, had higher educational level and breastfed for a longer period than mothers of children not included in the present analysis (Table S2). Table 1 shows the main characteristics of the study sample. Approximately $17 \%$ of mothers reported that they smoked during pregnancy and $37 \%$ had a high educational level (university). Approximately 5\% of the children had low birth 
weight $(<2500 \mathrm{~g})$ and $38 \%$ were classified in the BMI trajectory with average birth size and slower BMI gain (reference category).

\section{Associations of early childhood BMI trajectories with lung function at seven years}

Figure 2 and Table S3 show the adjusted associations between BMI trajectories up to four years and lung function at seven years. Compared to children with average birth size and slower BMI gain (reference), children with higher birth size and accelerated BMI gain had higher percent predicted FVC (3.3\% [95\% CI: 1.0 to 5.6]) and lower percent predicted $\mathrm{FEV}_{1} / \mathrm{FVC}$ ratio (-1.5\% [-2.9 to -0.1$])$ at seven years. Similarly, children with lower birth size and accelerated BMI gain had higher percent predicted FVC (2.8\% [0.5 to 5.0]) and tended to have lower percent predicted $\mathrm{FEV}_{1} / \mathrm{FVC}$ ratio ( $-1.3 \%$ [-2.7 to 0.1$\left.]\right)$ than children in the reference category. In contrast, children with lower birth size and slower BMI gain had lower percent predicted FVC (-3.1\% [ -5.2 to -0.9$])$ and tended to have lower $\mathrm{FEV}_{1}$ (-1.9\% [-4.1 to 0.3]), but higher percent predicted $\mathrm{FEV}_{1} / \mathrm{FVC}$ $(1.1 \%$ [- 0.2 to 2.4$])$ than children at the reference category. Finally, children with higher birth size and slower BMI gain did not differ from the reference category in lung function values. We found no significant associations of $\mathrm{BMI}$ trajectories with $\mathrm{FEF}_{25-75}$.

We observed a statistically significant interaction by sex of the association between accelerated BMI gain and higher $\mathrm{FEV}_{1}$, which was only present in girls ( $\mathrm{p}=0.075$, Table S4). The association of accelerated BMI gain with FVC was stronger in girls than in boys, while the association with $\mathrm{FEV}_{1} / \mathrm{FVC}$ was stronger in boys, without presence of statistical interaction.

The direction of the observed associations remained stable in all sensitivity analyses (Tables S5 to S9). However, exclusion of children with extreme lung function values resulted in the attenuation of some $\mathrm{FEV}_{1} / \mathrm{FVC}$ effect estimates (Table S7). Also, models restricted to children with at least two acceptable manoeuvres reproducible within $150 \mathrm{~mL}$ showed increased effect estimates for the group with higher birth size and accelerated BMI gain (Table S9).

\section{DISCUSSION}

\section{Main findings}

In this prospective population-based study we found that BMI trajectories from birth to four years relate to lung function at seven years. Specifically, we found that: (i) children with accelerated BMI gain had higher FVC and lower $\mathrm{FEV}_{1} / \mathrm{FVC}$ ratio at seven years either if they departed from lower or higher birth size, (ii) children with lower birth size and slower BMI gain had lower FVC and $\mathrm{FEV}_{1}$, but higher $\mathrm{FEV}_{1} / \mathrm{FVC}$ ratio at seven years (although the effect estimates for $\mathrm{FEV}_{1}$ and 
$\mathrm{FEV}_{1} / \mathrm{FVC}$ were imprecise), and (iii) we found no associations of BMI trajectories with $\mathrm{FEF}_{25-75}$ at seven years.

\section{Comparison with previous studies}

Our finding that accelerated BMI gain in the first four years of life is associated with higher FVC and lower $\mathrm{FEV}_{1} / \mathrm{FVC}$ ratio at seven years is in line with previous longitudinal studies [10-13], which measured early childhood growth using different parameters. The most recent study using data from the Generation R Study showed that peak weight velocity and BMI at adiposity peak, derived from individual growth trajectories in the first three years of life, were associated with higher FVC and $\mathrm{FEV}_{1}$ but lower $\mathrm{FEV}_{1} / \mathrm{FVC}$ ratio at ten years [13]. Peak weight velocity and BMI at adiposity peak represent accelerated BMI gain particularly in the first year of life, which is the period of fastest growth, as reflected in our trajectories (Figure 1). Similarly, another study using data from the same cohort found that accelerated foetal growth followed by accelerated infant weight growth up to one year (defined as growth percentile change between time periods) were associated with higher $\mathrm{FVC}$ and lower $\mathrm{FEV}_{1} / \mathrm{FVC}$ ratio at ten years [12]. An important contribution from our study is that, because we distinguished two patterns of accelerated BMI gain (departing from higher and lower birth size), we were able to demonstrate that the effects of accelerated weight gain on lung function do not depend on birth size. Specifically, we observed that accelerated BMI gain was associated with higher FVC at 7 years even if children departed from low birth size. This finding is in line with a previous study showing that children with intrauterine growth restriction who showed weight catch-up growth in the first nine years of life (calculated as the difference between two time points) had higher spirometry measures at age nine years than those without catch-up [6]. Another study also showed that weight gain during the first year of life (defined as the difference between two time points) was associated with higher adult lung function independently of birth weight [21].

We also found that children in the trajectory with lower birth size and slower BMI gain had lower $\mathrm{FVC}$ and $\mathrm{FEV}_{1}$ at seven years than the reference trajectory (although the estimate for $\mathrm{FEV}_{1}$ was imprecise), which is consistent with existing literature. Previous studies have reported that children with low birth weight or smaller birth size have decreased lung function compared to children with normal birth weight in childhood [6-11]. In addition, these children had higher $\mathrm{FEV}_{1} / \mathrm{FVC}$ ratio at seven years (although the estimate was imprecise), which is in line with previous research reporting an association between smaller birth size and higher ratio in childhood $[10,11]$.

We found no association between early childhood growth and $\mathrm{FEF}_{25-75}$ at seven years. This finding is in contrast with a previous study showing that rapid weight gain during the first three months of life (derived from individual growth trajectories) was associated with a decreased $\mathrm{FEF}_{25-75}$ at 
eight years [10]. This discrepancy may be attributed to different definitions of childhood growth and different exposure assessment periods (i.e. first three months $v s$. first four years), as well as to differences in sample size.

\section{Interpretation of results}

There are three potential mechanisms to explain the associations of accelerated BMI gain in early childhood with higher FVC and lower $\mathrm{FEV}_{1} / \mathrm{FVC}$ in later childhood. First, it is possible that accelerated BMI gain during early childhood has greater influence on lung volume than airway growth. This phenomenon is known as dysanapsis and reflects an incongruence between (faster) growth in lung volume and airway length, and (slower) increase in airway calibre [22,23]. Dysanapsis has been linked with clinical alterations in children with asthma [23] and may be a risk factor for respiratory diseases in later life. Second, it is plausible that accelerated BMI gain is accompanied by accumulation of adipose tissue, which could lead to airflow limitation (as measured by a lower $\mathrm{FEV}_{1} / \mathrm{FVC}$ ) by means of inflammatory processes. Adipose tissue is a source of pro-inflammatory factors, which can have local effects on the lungs causing structural alterations of the airways [24-26]. This inflammatory hypothesis is supported by a previous longitudinal study showing that higher fat mass during childhood was associated with lower $\mathrm{FEV}_{1} / \mathrm{FVC}$ levels in adolescence [27], and by another study showing that subjects with higher BMI had higher adipose tissue and inflammatory cells within the airway wall [26]. Finally, we cannot rule out the possibility that the association of accelerated BMI gain with lower FEV $1 / F V C$ ratio is due to mathematical artefact, since accelerated BMI gain was more strongly associated with FVC than with $\mathrm{FEV}_{1}$ in the present study. Further studies with available measures of early growth, inflammatory markers, adipose tissue levels and lung structure are needed to understand the potential underlying mechanisms of this association.

A potential explanation for the association of lower birth size and slower BMI gain with lower $\mathrm{FVC}$ and $\mathrm{FEV}_{1}$ at seven years is restricted foetal growth, since it may be a common cause of both lower birth size and disrupted lung function. Although the respiratory system continues developing until early adulthood, the majority of airway and alveoli development takes place in utero $[3,28]$. Several animal studies have reported that restricted foetal growth affects normal lung development causing structural alterations $[29,30]$, which may affect lung function in childhood. In contrast to children with lower birth size and accelerated BMI gain, children with lower birth size and slower BMI gain may not be able to compensate for these lung alterations during the first years of life.

\section{Implications}

The findings of the present study have important implications for research and public health. Our study shows that early childhood BMI trajectories are a useful tool to identify growth patterns 
associated with poor respiratory health. BMI trajectories, which can be estimated using information collected routinely in medical records, represent an accurate way to study early growth that can be easily interpreted for paediatricians and the general public. In addition, our findings, together with existing literature, support that early childhood growth impacts lung function development, and therefore may affect future respiratory health. Since weight growth is affected by modifiable factors, public health interventions promoting healthy lifestyles (e.g. healthy eating and physical activity) in early childhood may help to improve lung function and reduce respiratory morbidity in adulthood.

\section{Strengths and limitations}

Strengths of the present study are the longitudinal design and the population-based nature of the INMA cohort. Also, the availability of BMI trajectories from birth to four years allowed us to estimate the association of early growth with lung function accounting simultaneously for birth size and BMI gain. In addition, by using BMI trajectories as a marker of early growth we took into account weight and height changes during the first years of life simultaneously, while most of previous studies have focused only on weight growth [11,12], or have analysed weight and height separately $[10,13]$.

Our study also has some limitations, which include the potential selection bias due to the fact that mothers of children included in the study were older at pregnancy and had a higher educational level than mothers of children not included but participated in the INMA birth cohort. Although we were able to account for a wide range of potential confounders (including gestational age), residual confounding may be a concern as we did not have information on physical activity or diet before four years nor on non-allergic maternal asthma, all of which could be related to BMI growth and lung function. Another potential limitation of this study is the regional basis of the sample which may not allow the generalizability of our results to populations with different environmental and lifestyle factors. Finally, we used BMI as a marker of body growth but BMI is limited by its inability to distinguish between muscle and fat mass, which have different effects on lung function [27]. Although BMI trajectories in early childhood could be a good predictor of later body composition [31], further research using detailed measures of body composition is needed to provide insight into the effect of body composition during early childhood on later respiratory health.

\section{Conclusion}

In conclusion, we found that, independently of birth size, children with accelerated BMI gain in early childhood had higher lung function at seven years, but also showed airflow limitation. In contrast, children with lower birth size and slower BMI gain in early childhood had lower lung function at seven years. This study shows that BMI trajectories during the first years of life can 
identify growth patterns associated with poor respiratory health in later childhood. Our results, together with existing literature, support that early postnatal growth is likely to play a role in lung function development during childhood, and therefore can affect respiratory health in later life. Public health strategies aiming to reduce respiratory health problems may need to target early weight growth. 


\section{CONTRIBUTORS}

GPP, MC and JG-A designed the study. GPP conducted the statistical analyses and wrote the initial draft. MC and JG-A had full access to all the data in the study and take responsibility for the integrity of the data and the accuracy of the data analysis. All authors provided substantial contributions to the conception or design of the work, or the acquisition, analysis or interpretation of data for the work, revised the manuscript for important intellectual content, approved the final version, and agreed to be accountable for all aspects of the work.

\section{FUNDING}

This study was funded by Grants from EU (FP7-ENV-2011 cod 282957, 261357 and HEALTH.2010.2.4.5-1), Instituto de Salud Carlos III (Red INMA G03/176, CB06/02/0041; FISFEDER: PI041436; PI081151, PI06/0867, PI09/00090 and PI13/02187, PI03/1615, PI04/1509, PI04/1112, PI04/1931, PI05/1079, PI05/1052, PI06/1213, PI07/0314, PI09/02647, PI11/01007, PI11/02591, PI11/02038, PI13/1944, PI13/2032, PI14/00891, PI14/01687, PI16/1288, and PI17/00663; Miguel Servet-FEDER CP11/00178, CP15/00025, and CPII16/00051), Generalitat Valenciana: FISABIO (UGP 15-230, UGP-15-244, and UGP-15-249), Alicia Koplowitz Foundation 2017, CIBERESP, Generalitat de Catalunya-CIRIT 1999 SGR 00241, Generalitat de Catalunya-AGAUR 2009 SGR 501, Fundació La marató de TV3 (090430), Department of Health of the Basque Government (2005111093, 2009111069, 2013111089 and 2015111065), the Provincial Government of Gipuzkoa (DFG06/002, DFG08/001 and DFG15/221). ISGlobal is a member of the CERCA Programme, Generalitat de Catalunya

The funding sources had no involvement in the study design, the collection, analysis and interpretation of data or in the writing of the report and in the decision to submit the article for publication.

\section{ACKNOWLEDGMENTS}

We thank all the study participants for their generous collaboration and the interviewers for their assistance in contacting the families and administering the questionnaires. A full roster of the INMA Project Investigators can be found at http://www.proyectoinma.org/en/inma-project/inmaproject-researchers/

\section{COMPETING INTERESTS}

JG-A reports personal fees from Esteve, Chiesi and AstraZeneca, outside the submitted work. Other authors declare no competing interests related to this work 


\section{LIST OF TABLES}

Table 1. Characteristics of the study sample

\section{LIST OF FIGURES}

Figure 1. Body mass index (BMI) z-score trajectories from birth to four years

Adapted from Montazeri P., et al. Obesity 2018

$\dagger$ Reference category

Figure 2. Adjusted associations of early childhood body mass index (BMI) trajectories with lung function at seven years.

Abbreviations: $\mathrm{FEF}_{25-75}$ : forced expiratory flow 25-75\%; $\mathrm{FEV}_{1}$ : Forced expiratory volume in 1 second; FVC: forced vital capacity; Coef: regression coefficient; $95 \%$ CI: 95\% confidence intervals.

All models were adjusted for maternal age at delivery, pre-pregnancy BMI, history of allergy-related disease, educational level, smoking during pregnancy, and child's gestational age, duration of any breastfeeding and lower respiratory tract infections during the first year.

Due to missing values in the covariates, the study sample included in the multivariable analysis was 1,195 for $\mathrm{FVC}, \mathrm{FEV}_{1}$ and $\mathrm{FEV}_{1} / \mathrm{FVC}$, and 1,193 for $\mathrm{FEF}_{25-75}$.

* p-value $<0.05$ 
n (\%), mean (SD) or

median $\left(\mathbf{P}_{25}-\mathbf{P}_{75}\right)$

\section{Maternal characteristics}

Age at delivery (years)

$30.9(0.1)$

Pre-pregnancy BMI $\left(\mathrm{kg} / \mathrm{m}^{2}\right)$

22.6 (20.8 to 25.2$)$

History of allergy-related disease ${ }^{\dagger}$

$335(26.7 \%)$

Smoking during pregnancy

Never smoker

$573(46.2 \%)$

Smoking before pregnancy

$458(37.0 \%)$

Smoking during pregnancy

$208(16.8 \%)$

Educational level

Primary or less

$263(21.2 \%)$

Secondary

$515(41.4 \%)$

University

$465(37.4 \%)$

\section{Child characteristics}

Sex: girl

$622(49.5 \%)$

Birth weight $(\mathrm{g})$

$3,258(458)$

Low birth weight $(<2,500 \mathrm{~g})$

$65(5.2 \%)$

Gestational age (weeks)

39.9 (38.9 to 40.7$)$

Preterm birth ( $<37$ weeks)

$48(3.8 \%)$

Duration of any breastfeeding (weeks)

25.9 (10.7 to 43.4$)$

Low respiratory tract infections during the first year

$438(35.4 \%)$

Age at 7 years (years)

7.5 (7.0 to 7.8$)$

Height at 7 years $(\mathrm{cm})$

$124.7(6.3)$

Asthma at 7 years **

$115(9.2 \%)$

BMI trajectories from birth to four years

Higher birth size - accelerated BMI gain

$137(10.9 \%)$

Lower birth size - accelerated BMI gain

$145(11.6 \%)$

Higher birth size - slower BMI gain

Average birth size - slower BMI gain (Reference)

$483(38.4 \%)$

Lower birth size - slower BMI gain

$160(12.7 \%)$

Lung function at 7 years ${ }^{\ddagger}$

Percent predicted FVC (\%)

$101.8(12.0)$

Percent predicted $\mathrm{FEV}_{1}(\%)$

$104.8(11.9)$

Percent predicted $\mathrm{FEV}_{1} / \mathrm{FVC}(\%)$

$96.7(7.5)$

Percent predicted $\mathrm{FEF}_{25-75}(\%)$

$95.1(23.8)$

Abbreviations: BMI: body mass index; $\mathrm{FEV}_{1}$ : forced expiratory volume in 1 second; $\mathrm{FEF}_{25-75}$ : forced expiratory flow at $25-75 \%$ of the pulmonary volume; FVC: forced vital capacity 
"Some variables had missing values: Maternal characteristics: 6 in age at delivery, 8 in pre-pregnancy BMI, 1 in allergy-related disease, 18 in smoking, 14 in educational level; Child characteristics: 3 in birth weight, 17 in duration of any breastfeeding, 18 in lower respiratory tract infections during the first year, 3 in asthma at 7 years, 2 in $\mathrm{FEF}_{25-75}$ at 7 years

$\dagger$ Defined as reporting at least one of the following: allergic asthma, atopic dermatitis, eczema or allergic rhinitis

** We defined current asthma based on a positive answer to at least two of the following questions: lifetime doctor diagnosis of asthma, use of medicines for asthma or breathing difficulties in the last 12 months, and wheezing or whistling in the chest at any time in the last 12 months.

${ }^{\ddagger}$ Calculated by using Global Lung Function Initiative (GLI) 2012 prediction equations 


\section{REFERENCES}

1 Kajekar R. Environmental factors and developmental outcomes in the lung. Pharmacol Ther 2007;114:129-45. doi:10.1016/j.pharmthera.2007.01.011

2 Narang I, Bush A. Early origins of chronic obstructive pulmonary disease. Semin Fetal Neonatal Med 2012;17:112-8. doi:10.1016/j.siny.2012.01.002

3 Stocks J, Hislop A, Sonnappa S. Early lung development: Lifelong effect on respiratory health and disease. Lancet Respir Med 2013;1:728-42. doi:10.1016/S2213-2600(13)70118-8

Burri PH. Structural aspects of postnatal lung development - Alveolar formation and growth. Biol Neonate 2006;89:313-22. doi:10.1159/000092868

Carraro S, Scheltema N, Bont L, et al. Early-life origins of chronic respiratory diseases: Understanding and promoting healthy ageing. Eur Respir J 2014;44:1682-96. doi:10.1183/09031936.00084114

Kotecha SJ, Watkins WJ, Heron J, et al. Spirometric lung function in school-age children: Effect of intrauterine growth retardation and catch-up growth. Am J Respir Crit Care Med 2010;181:969-74. doi:10.1164/rccm.200906-0897OC

Dezateux C, Lum S, Hoo A-F, et al. Low birth weight for gestation and airway function in infancy: exploring the fetal origins hypothesis. Thorax 2004;59:60-6.

Lucas JS, Inskip HM, Godfrey KM, et al. Small size at birth and greater postnatal weight gain: Relationships to diminished infant lung function. Am J Respir Crit Care Med 2004;170:534-40. doi:10.1164/rccm.200311-1583OC

9 Lum S, Hoo AF, Dezateux C, et al. The association between birthweight, sex, and airway function in infants of nonsmoking mothers. Am J Respir Crit Care Med 2001;164:2078-84. doi:10.1164/ajrccm.164.11.2104053

Sonnenschein-Van Der Voort AMM, Howe LD, Granell R, et al. Influence of childhood growth on asthma and lung function in adolescence. J Allergy Clin Immunol 2015;135:1435-1443e7. doi:10.1016/j.jaci.2014.10.046

11 Den Dekker HT, Sonnenschein-Van Der Voort AMM, De Jongste JC, et al. Early growth characteristics and the risk of reduced lung function and asthma: A meta-analysis of 25,000 children. J Allergy Clin Immunol 2016;137:1026-35. doi:10.1016/j.jaci.2015.08.050

12 Den Dekker HT, Jaddoe VWV, Reiss IK, et al. Fetal and infant growth patterns and risk of lower lung function and asthma: The Generation R study. Am J Respir Crit Care Med 2018;197:18392. doi:10.1164/rccm.201703-06310C

13 Casas M, den Dekker HT, Kruithof CJ, et al. The effect of early growth patterns and lung function on the development of childhood asthma: a population based study. Thorax 2018;:thoraxjnl-2017-211216. doi:10.1136/thoraxjnl-2017-211216

14 Montazeri P, Vrijheid M, Martinez D, et al. Maternal Metabolic Health Parameters During Pregnancy in Relation to Early Childhood BMI Trajectories. Obesity 2018;26:588-96. doi:10.1002/oby.22095

15 Guxens M, Ballester F, Espada M, et al. Cohort Profile: the INMA-INfancia y Medio Ambiente(Environment and Childhood) Project. Int J Epidemiol 2012;41:930-40. doi:10.1093/ije/dyr054

16 De Onis M. 4.1 The WHO Child Growth Standards. World Rev Nutr Diet 2015;113:278-94. doi:10.1159/000360352

17 Fernández-Barrés S, Vrijheid M, Manzano-Salgado CB, et al. The Association of Mediterranean Diet during Pregnancy with Longitudinal Body Mass Index Trajectories and Cardiometabolic Risk in Early Childhood. J Pediatr 2019;206:119-127.e6. doi:10.1016/j.jpeds.2018.10.005

18 Miller MR, Hankinson J, Brusasco V, et al. Standardisation of spirometry. Eur Respir J 2005;26:319-38. doi:10.1183/09031936.05.00034805 
Quanjer PH, Stanojevic S, Cole TJ, et al. Multi-ethnic reference values for spirometry for the 395-yr age range: The global lung function 2012 equations. Eur Respir J 2012;40:1324-43. doi:10.1183/09031936.00080312

20 Hohmann C, Keller T, Gehring U, et al. Sex-specific incidence of asthma, rhinitis and respiratory multimorbidity before and after puberty onset: individual participant meta-analysis of five birth cohorts collaborating in MeDALL. BMJ Open Resp Res 2019;6:460. doi:10.1136/bmjresp-2019000460

21 Canoy D, Pekkanen J, Elliott P, et al. Early growth and adult respiratory function in men and women followed from the fetal period to adulthood. Thorax 2007;62:396-402. doi:10.1136/thx.2006.066241

22 Green M, Mead J, Turner JM. Variability of maximum expiratory flow-volume curves. J Appl Physiol 1974;37:67-74. doi:10.1152/jappl.1974.37.1.67

23 Forno E, Weiner DJ, Mullen J, et al. Obesity and airway dysanapsis in children with and without asthma. Am J Respir Crit Care Med 2017;195:314-23. doi:10.1164/rccm.201605-1039OC

24 Greenberg AS, Obin MS. Obesity and the role of adipose tissue in inflammation and metabolism. Am J Clin Nutr 2006;83:461S-465S. doi:10.1093/ajcn/83.2.461S

Boulet LP. Asthma and obesity. Clin Exp Allergy 2013;43:8-21. doi:10.1111/j.13652222.2012.04040.x

26 Elliot JG, Donovan GM, Wang KC, et al. Fatty Airways: Implications for Obstructive Disease. Eur Respir J 2019;54:1900857. doi:10.1183/13993003.00857-2019

27 Peralta GP, Fuertes E, Granell R, et al. Childhood Body Composition Trajectories and Adolescent Lung Function. Findings from the ALSPAC study. Am J Respir Crit Care Med 2019;200:75-83. doi:10.1164/rccm.201806-1168OC

28 Narayanan M, Owers-Bradley J, Beardsmore CS, et al. Alveolarization Continues during Childhood and Adolescence. Am J Respir Crit Care Med 2012;185:186-91. doi:10.1164/rcem.201107-13480C

29 Lipsett J, Tamblyn M, Madigan K, et al. Restricted fetal growth and lung development: A morphometric analysis of pulmonary structure. Pediatr Pulmonol 2006;41:1138-45. doi:10.1002/ppul.20480

30 Maritz GS, Cock ML, Louey S, et al. Effects of fetal growth restriction on lung development before and after birth: A morphometric analysis. Pediatr Pulmonol 2001;32:201-10. doi:10.1002/ppul.1109

31 Slining MM, Herring AH, Popkin BM, et al. Infant BMI trajectories are associated with young adult body composition. J Dev Orig Health Dis 2013;4:56-68. doi:10.1017/S2040174412000554 
Early childhood growth is associated with lung function at seven years: a prospective population-based study

Gabriela P. Peralta, Alicia Abellan, Parisa Montazeri, Mikel Basterrechea, Ana Esplugues, Sandra González, Célina Roda, Loreto Santa-Marina, Jordi Sunyer, Martine Vrijheid, Maribel Casas*, Judith Garcia-Aymerich*

*Shared last authorship

\section{SUPPLEMENTARY INFORMATION}

Contents

Methods: Definition of asthma at 7 years

Methods: Sensitivity analyses

Figure S1. Flowchart of the study sample

Figure S2. Directed acyclic graph of hypothesised associations between study variables

Table S1. Descriptive statistics of weight and length/height at birth and at one and four years according to BMI trajectories

Table S2. Characteristics of included and non-included participants

Table S3. Adjusted associations of early childhood BMI trajectories with lung function at seven years

Table S4. Adjusted associations of early childhood BMI trajectories with lung function at seven years - Stratified by sex

Table S5. Adjusted associations early childhood BMI trajectories with lung function at seven years - Excluding children with current asthma at seven years

Table S6. Adjusted associations of early childhood BMI trajectories with lung function at seven years - Excluding children from mothers who smoked at pregnancy

Table S7. Adjusted associations of early childhood BMI trajectories with lung function at seven years - Excluding children with extreme outcome values (<p1 \& >p99)

Table S8. Adjusted associations of early childhood BMI trajectories with lung function at seven years - Excluding preterm children

Table S9. Adjusted associations of early childhood BMI trajectories with lung function at seven years - Restricting models to children with at least two acceptable manoeuvres reproducible within $150 \mathrm{~mL}$ 


\section{Definition of asthma at 7 years}

Information on asthma at seven years was collected through the International Study of Asthma and Allergies in Childhood (ISAAC) questionnaire completed by parents. As previously agreed in the MeDALL (Mechanisms of the Development of Allergy) project, we defined current asthma based on a positive answer to at least two of the following questions: 1) 'Has your child ever been diagnosed by a doctor as having asthma?'; 2) 'Has your child taken any medicines for asthma (including inhalers, nebulizers, tablets or liquid medicines) or breathing difficulties (chest tightness, shortness of breath) in the last 12 months?'; 3) Has your child had wheezing or whistling in the chest at any time in the last 12 months?'[1].

\section{Reference:}

1 Hohmann C, Keller T, Gehring U, et al. Sex-specific incidence of asthma, rhinitis and respiratory multimorbidity before and after puberty onset: individual participant metaanalysis of five birth cohorts collaborating in MeDALL. BMJ Open Resp Res 2019;6:460. doi:10.1136/bmjresp-2019-000460

\section{Methods: Sensitivity analyses}

To assess the robustness of our results we performed several sensitivity analyses. We excluded children with current asthma at seven years, children from mothers who smoked during pregnancy, children with extreme lung function values (below percentile one and above percentile 99) and children born prematurely in separate analyses to assess whether the observed associations were influenced by these subsamples. We also restricted models to children with at least two acceptable manoeuvres reproducible within $150 \mathrm{~mL}$ to account for potential misclassification in lung function. 


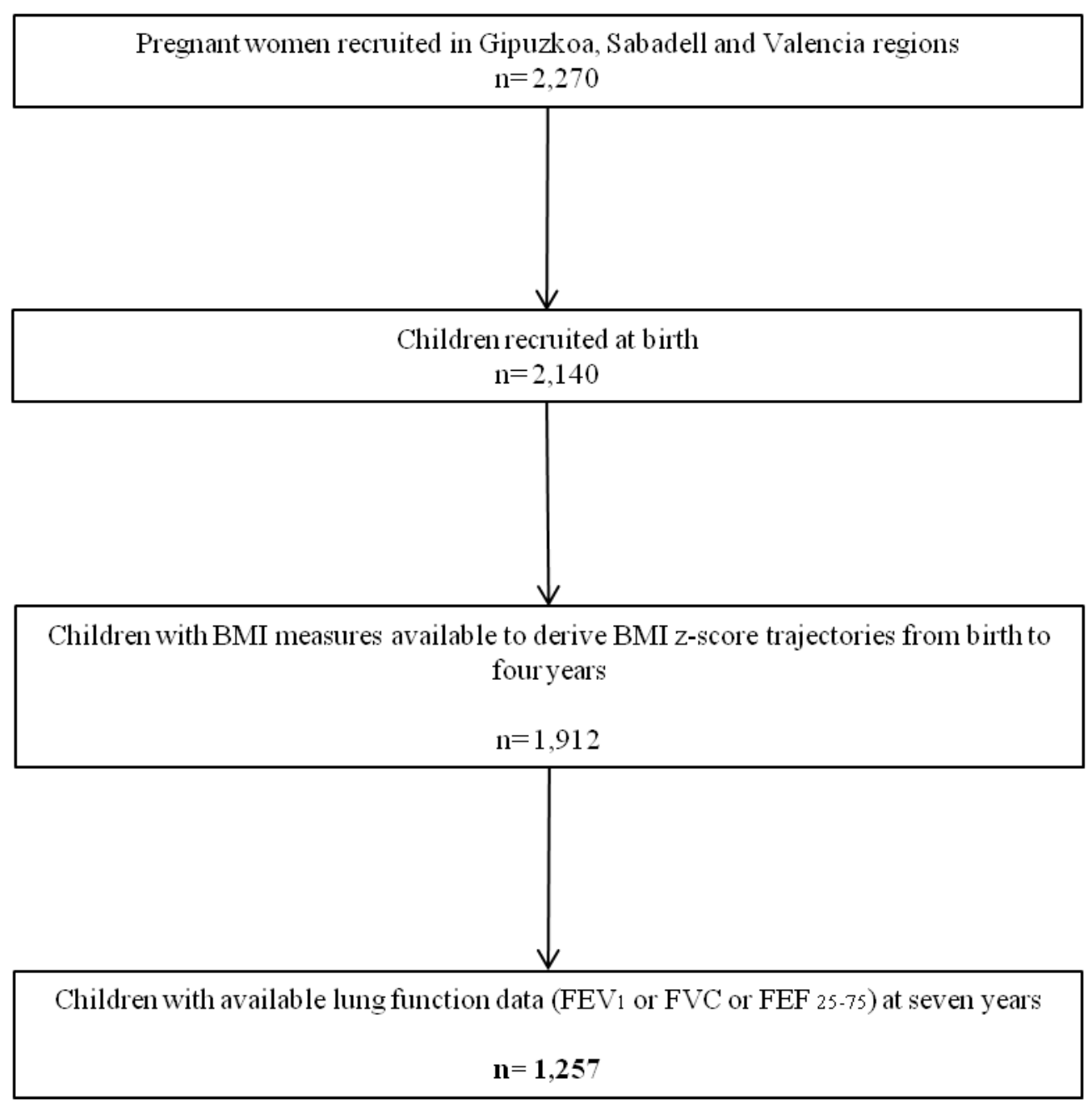

\section{Figure S1. Flowchart of the study sample}

Abbreviations: $\mathrm{BMI}$, body mass index; $\mathrm{FEV}_{1}$ : forced expiratory volume in 1 second; $\mathrm{FEF}_{25-75}$ : forced expiratory flow at $25-75 \%$ of the pulmonary volume; FVC: forced vital capacity 


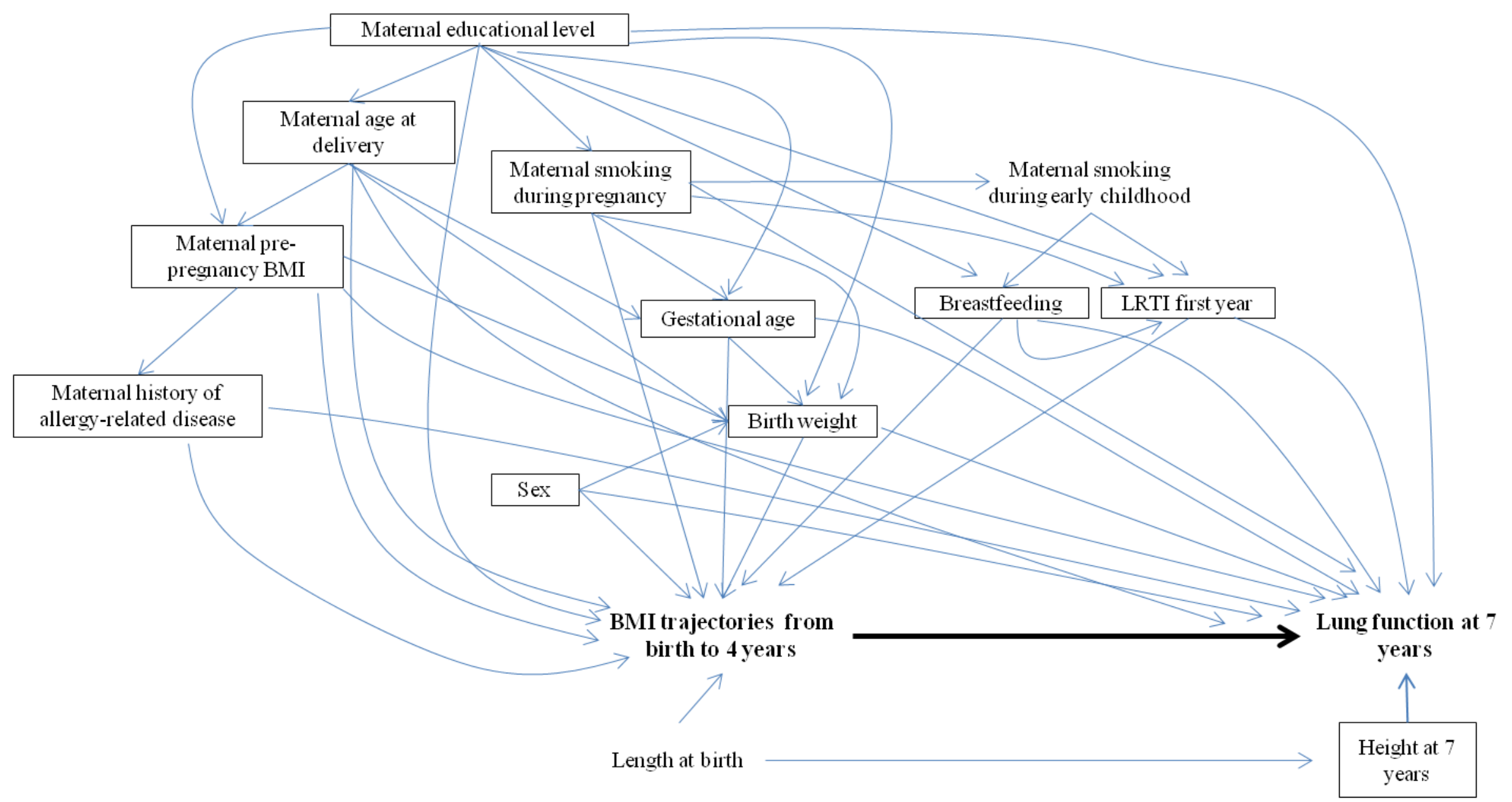

Figure S2. Directed acyclic graph of hypothesised associations between study variables

Variables with black squares represent the minimal adjustment set of covariables required to study the association of BMI trajectories from birth to four years with lung function at seven years. Abbreviations: BMI, body mass index; LRTI, lower respiratory tract infections 
Table S1. Distribution of weight and length/height at birth and at one and four years according to BMI trajectories

\begin{tabular}{|c|c|c|c|c|c|c|c|}
\hline & $\mathbf{n}$ & $\begin{array}{c}\text { Higher birth size - } \\
\text { accelerated BMI gain } \\
\mathbf{n}=137(\mathbf{1 0 . 9 \%})\end{array}$ & $\begin{array}{c}\text { Higher birth size - } \\
\text { slower BMI gain } \\
\text { n=145 (11.6\%) } \\
\end{array}$ & $\begin{array}{c}\text { Lower birth size - } \\
\text { accelerated BMI gain } \\
\mathbf{n}=332(\mathbf{2 6 . 4 \%})\end{array}$ & $\begin{array}{c}\text { Average birth size - } \\
\text { slower BMI gain } \\
n=483(38.4 \%) \\
\end{array}$ & $\begin{array}{c}\text { Lower birth size - } \\
\text { slower BMI gain } \\
\text { n=160 }(12.7 \%) \\
\end{array}$ & $\begin{array}{c}\text { Overall } \\
\mathrm{n}=\mathbf{1 , 2 5 7} \\
(\mathbf{1 0 0} \%) \\
\end{array}$ \\
\hline \multicolumn{8}{|l|}{ Weight } \\
\hline Birth weight (kg) & 1,254 & $3.5(0.5)$ & $3.4(0.4)$ & $3.1(0.4)$ & $3.2(0.4)$ & $3.0(0.5)$ & $3.3(0.5)$ \\
\hline Weight at 1 year $(\mathrm{kg})$ & 1,143 & $11.5(1.1)$ & $10.3(0.9)$ & $11.0(1.1)$ & $9.7(0.9)$ & $9.1(0.9)$ & $10.1(1.2)$ \\
\hline Weight at 4 year $(\mathrm{kg})$ & 1,200 & $20.7(2.9)$ & $18.2(2.1)$ & $20.2(3.1)$ & $17.6(2.1)$ & $16.1(1.9)$ & $18.2(2.7)$ \\
\hline \multicolumn{8}{|l|}{ Height } \\
\hline Birth length $(\mathrm{cm})$ & 1,224 & $49.8(2.0)$ & $49.9(1.9)$ & $49.1(2.4)$ & $49.6(2.1)$ & $49.0(2.6)$ & $49.6(2.2)$ \\
\hline Height at 1 year $(\mathrm{cm})$ & 1,143 & $77.7(3.0)$ & 76.7 (2.9) & $77.2(3.3)$ & $76.4(2.9)$ & $76.3(3.0)$ & $76.7(3.0)$ \\
\hline Height at 4 year $(\mathrm{cm})$ & 1,200 & $106.7(4.4)$ & $105.2(4.3)$ & $107.2(4.7)$ & $105.5(4)$ & $104.6(4.4)$ & $105.6(4.3)$ \\
\hline
\end{tabular}

Values are means and standard deviations. Abbreviations: BMI: body mass index 
Table S2. Characteristics of included and non-included participants

\begin{tabular}{|c|c|c|c|}
\hline & $\begin{array}{c}\text { Participants } \\
(\mathbf{n}=\mathbf{1}, 257) \\
\mathbf{n}(\%), \text { mean }(\mathrm{SD}) \text { or } \\
\text { median }\left(\mathbf{P}_{25}-\mathbf{P}_{75}\right)\end{array}$ & $\begin{array}{c}\text { Non-participants } \\
(\mathbf{n}=\mathbf{1 , 0 1 3}) \\
\mathrm{n}(\%), \text { mean }(\mathrm{SD}) \text { or } \\
\text { median }\left(\mathrm{P}_{25}-\mathrm{P}_{75}\right)\end{array}$ & $p$-value* \\
\hline \multicolumn{4}{|l|}{ Maternal characteristics } \\
\hline Age at delivery (years) & $30.9(0.1)$ & $29.7(0.2)$ & $<0.001$ \\
\hline Pre-pregnancy BMI $\left(\mathrm{kg} / \mathrm{m}^{2}\right)$ & $22.6(20.8$ to 25.2$)$ & $22.5(20.7$ to 25.1$)$ & 0.559 \\
\hline History of allergy-related disease $\dagger$ & $335(26.7 \%)$ & $246(25.2 \%)$ & 0.417 \\
\hline \multicolumn{4}{|l|}{ Smoking during pregnancy } \\
\hline Never smoker & $573(46.2 \%)$ & $361(41.5 \%)$ & 0.061 \\
\hline Smoking before pregnancy & $458(37.0 \%)$ & $334(38.5 \%)$ & \\
\hline Smoking during pregnancy & $208(16.8 \%)$ & $173(20.0 \%)$ & \\
\hline \multicolumn{4}{|l|}{ Educational level } \\
\hline Primary or less & $263(21.2 \%)$ & $312(33.4 \%)$ & $<0.001$ \\
\hline Secondary & $515(41.4 \%)$ & $376(40.3 \%)$ & \\
\hline University & $465(37.4 \%)$ & $245(26.3 \%)$ & \\
\hline \multicolumn{4}{|l|}{ Child characteristics } \\
\hline Sex: girls & $622(49.5 \%)$ & $415(47.2 \%)$ & 0.302 \\
\hline Birth weight (grams) & $3,258(458)$ & $3,256(521)$ & 0.764 \\
\hline Low birth weight $(<2,500 \mathrm{~g})$ & $65(5.2 \%)$ & $45(5.2 \%)$ & 0.994 \\
\hline Gestational age (weeks) & 39.9 (38.9 to 40.7$)$ & $39.9(38.9$ to 40.6$)$ & 0.959 \\
\hline Preterm birth (<37 weeks gestation) & $48(3.8 \%)$ & $40(4.6 \%)$ & 0.390 \\
\hline Duration of any breastfeeding (weeks) & $25.9(10.7$ to 43.4$)$ & $21.8(5.7$ to 39$)$ & 0.001 \\
\hline $\begin{array}{l}\text { Low respiratory tract infections during the } \\
\text { first year }\end{array}$ & $438(35.4 \%)$ & $240(34.3 \%)$ & 0.637 \\
\hline
\end{tabular}

Abbreviations: BMI: body mass index

$\dagger$ Defined as reporting at least one of the following: allergic asthma, atopic dermatitis, eczema or allergic rhinitis

*p-value for chi-squared, t-test or U-Mann Witney tests 
Table S3. Adjusted associations of early childhood BMI trajectories with lung function at seven years

\begin{tabular}{|c|c|c|c|c|c|c|c|c|}
\hline \multirow[b]{2}{*}{ BMI trajectories } & \multicolumn{2}{|c|}{$\begin{array}{c}\text { Percent predicted } \\
\text { FVC }(\%)\end{array}$} & \multicolumn{2}{|c|}{$\begin{array}{c}\text { Percent predicted } \\
\operatorname{FEV}_{1}(\%)\end{array}$} & \multicolumn{2}{|c|}{$\begin{array}{c}\text { Percent predicted } \\
\text { FEV }_{1} / \text { FVC }(\%)\end{array}$} & \multicolumn{2}{|c|}{$\begin{array}{l}\text { Percent predicted } \\
\text { FEF }_{25-75}(\%)\end{array}$} \\
\hline & Coef $(95 \%$ CI $)$ & $p$-value & Coef $(95 \%$ CI $)$ & $p$-value & Coef $(95 \%$ CI $)$ & $p$-value & Coef $(95 \%$ CI $)$ & $p$-value \\
\hline $\mathrm{n}$ & 1,195 & & 1,195 & & 1,195 & & 1,193 & \\
\hline Average birth size - Slower BMI gain & Reference & & Reference & & Reference & & Reference & \\
\hline Higher birth size - Accelerated BMI gain & $3.3(1.0$ to 5.6$)$ & 0.005 & $1.5(-0.9$ to 3.8$)$ & 0.215 & $-1.5(-2.9$ to -0.1$)$ & 0.031 & $-2.8(-7.4$ to 1.7$)$ & 0.222 \\
\hline Higher birth size - Slower BMI gain & $0.6(-1.1$ to 2.3$)$ & 0.480 & $1.1(-0.6$ to 2.8$)$ & 0.214 & $0.4(-0.6$ to 1.5$)$ & 0.407 & $1.7(-1.7$ to 5.1$)$ & 0.325 \\
\hline Lower birth size - Accelerated BMI gain & $2.8(0.5$ to 5.0$)$ & 0.016 & $1.2(-1.1$ to 3.5$)$ & 0.315 & $-1.3(-2.7$ to 0.1$)$ & 0.064 & $-1.9(-6.4$ to 2.6$)$ & 0.417 \\
\hline Lower birth size - Slower BMI gain & $-3.1(-5.2$ to -0.9$)$ & 0.006 & $-1.9(-4.1$ to 0.3$)$ & 0.098 & $1.1(-0.2$ to 2.4$)$ & 0.096 & $0.4(-3.9$ to 4.7$)$ & 0.858 \\
\hline
\end{tabular}

All models were adjusted for maternal age at delivery, pre-pregnancy BMI, history of allergy-related disease, educational level, smoking during pregnancy, and child's gestational age, duration of any breastfeeding and lower respiratory tract infections during the first year

Abbreviations: BMI: body mass index; $\mathrm{FEF}_{25-75}$ : forced expiratory flow 25-75\%; $\mathrm{FEV}_{1}$ : Forced expiratory volume in 1 second; FVC: forced vital capacity; Coef: regression coefficient: $95 \% \mathrm{CI}$; $95 \%$ confidence interval 
Table S4. Adjusted associations of early childhood BMI trajectories with lung function at seven years - Stratified by sex

\begin{tabular}{|c|c|c|c|c|c|c|c|c|}
\hline \multirow[b]{2}{*}{ BMI trajectories } & \multicolumn{2}{|c|}{$\begin{array}{c}\text { Percent predicted } \\
\text { FVC }(\%)\end{array}$} & \multicolumn{2}{|c|}{$\begin{array}{c}\text { Percent predicted } \\
\text { FEV }_{1}(\%)\end{array}$} & \multicolumn{2}{|c|}{$\begin{array}{l}\text { Percent predicted } \\
\text { FEV }_{1} / \text { FVC }(\%)\end{array}$} & \multicolumn{2}{|c|}{$\begin{array}{l}\text { Percent predicted } \\
\text { FEF }_{25-75}(\%)\end{array}$} \\
\hline & Coef $(95 \%$ CI $)$ & $p$-value & Coef $(95 \%$ CI $)$ & $p$-value & Coef $(95 \%$ CI $)$ & $p$-value & Coef $(95 \%$ CI $)$ & $p$-value \\
\hline \multicolumn{9}{|l|}{ Girls } \\
\hline $\mathrm{n}$ & 590 & & 590 & & 590 & & 588 & \\
\hline Average birth size - Slower BMI gain & Reference & & Reference & & Reference & & Reference & \\
\hline Higher birth size - Accelerated BMI gain & $5.6(2.2$ to 8.9$)$ & 0.001 & $4.5(1.2$ to 7.7$)$ & 0.007 & $-0.9(-2.8$ to 1.0$)$ & 0.370 & $0.3(-5.9$ to 6.5$)$ & 0.928 \\
\hline Higher birth size - Slower BMI gain & $1.9(-0.5$ to 4.3$)$ & 0.120 & $1.6(-0.8$ to 4$)$ & 0.186 & $-0.2(-1.6$ to 1.2$)$ & 0.806 & $0.8(-3.7$ to 5.3$)$ & 0.732 \\
\hline Lower birth size - Accelerated BMI gain & $4.5(1.2$ to 7.8$)$ & 0.007 & $3.2(0$ to 6.5$)$ & 0.051 & $-1.0(-2.9$ to 0.9$)$ & 0.316 & $0.5(-5.7$ to 6.7$)$ & 0.883 \\
\hline Lower birth size - Slower BMI gain & $-3.3(-6.6$ to -0.1$)$ & 0.045 & $-2.1(-5.4$ to 1.1$)$ & 0.193 & $1.4(-0.4$ to 3.3$)$ & 0.134 & $-0.9(-7.1$ to 5.2$)$ & 0.768 \\
\hline \multicolumn{9}{|l|}{ Boys } \\
\hline $\mathrm{n}$ & 605 & & 605 & & 605 & & 605 & \\
\hline Average birth size - Slower BMI gain & Reference & & Reference & & Reference & & Reference & \\
\hline Higher birth size - Accelerated BMI gain & $1.3(-1.8$ to 4.4$)$ & 0.420 & $-1.4(-4.7$ to 1.9$)$ & 0.395 & $-2.3(-4.4$ to -0.3$)$ & 0.025 & $-6.3(-13$ to 0.3$)$ & 0.062 \\
\hline Higher birth size - Slower BMI gain & $-0.3(-2.7$ to 2.1$)$ & 0.803 & $0.8(-1.7$ to 3.2$)$ & 0.543 & $1.0(-0.5$ to 2.6$)$ & 0.190 & $2.4(-2.6$ to 7.4$)$ & 0.340 \\
\hline Lower birth size - Accelerated BMI gain & $1.3(-1.7$ to 4.4$)$ & 0.388 & $-0.6(-3.8$ to 2.6$)$ & 0.727 & $-1.5(-3.5$ to 0.5$)$ & 0.146 & $-3.9(-10.4$ to 2.6$)$ & 0.239 \\
\hline Lower birth size - Slower BMI gain & $-3.2(-6.1$ to -0.3$)$ & 0.030 & $-2.3(-5.3$ to 0.8$)$ & 0.148 & $0.7(-1.2$ to 2.6$)$ & 0.471 & $-0.2(-6.3$ to 6.0$)$ & 0.957 \\
\hline$p$-value for sex interaction* & & 0.216 & & 0.075 & & 0.385 & & 0.410 \\
\hline
\end{tabular}

All models were adjusted for maternal age at pregnancy, pre-pregnancy BMI, history of allergy-related disease, educational level, smoking during pregnancy, and child's gestational age, duration of any breastfeeding and lower respiratory tract infections during the first year

Abbreviations: BMI: body mass index; $\mathrm{FEF}_{25-75}$, forced expiratory flow 25-75\%; FEV 1 : Forced expiratory volume in 1 second; FVC: forced vital capacity; Coef: regression coefficient: $95 \% \mathrm{CI}$; 95\% confidence interval

* p-value for the Wald test, which tests the overall significance of the interaction for all trajectory groups 
Table S5. Adjusted associations of early childhood BMI trajectories with lung function at seven years - Excluding children with current asthma at seven years

\begin{tabular}{|c|c|c|c|c|c|c|c|c|}
\hline \multirow[b]{2}{*}{ BMI trajectories } & \multicolumn{2}{|c|}{$\begin{array}{c}\text { Percent predicted } \\
\text { FVC }(\%)\end{array}$} & \multicolumn{2}{|c|}{$\begin{array}{l}\text { Percent predicted } \\
\text { FEV }_{1}(\%)\end{array}$} & \multicolumn{2}{|c|}{$\begin{array}{l}\text { Percent predicted } \\
\text { FEV }_{1} / \text { FVC }(\%)\end{array}$} & \multicolumn{2}{|c|}{$\begin{array}{l}\text { Percent predicted } \\
\text { FEF } 25-75(\%)\end{array}$} \\
\hline & Coef $(95 \%$ CI $)$ & $p$-value & Coef $(95 \%$ CI $)$ & $p$-value & Coef $(95 \%$ CI $)$ & $p$-value & Coef $(95 \%$ CI $)$ & $p$-value \\
\hline $\mathrm{n}$ & 1,087 & & 1,087 & & 1,087 & & 1,085 & \\
\hline Average birth size - Slower BMI gain & Reference & & Reference & & Reference & & Reference & \\
\hline Higher birth size - Accelerated BMI gain & $3.6(1.2$ to 5.9$)$ & 0.003 & $1.8(-0.6$ to 4.2$)$ & 0.149 & $-1.5(-3.0$ to -0.1$)$ & 0.038 & $-3.0(-7.7$ to 1.7$)$ & 0.214 \\
\hline Higher birth size - Slower BMI gain & 0.9 (-0.9 to 2.6$)$ & 0.323 & $1.1(-0.6$ to 2.9$)$ & 0.209 & $0.2(-0.8$ to 1.3$)$ & 0.662 & $1.3(-2.2$ to 4.8$)$ & 0.466 \\
\hline Lower birth size - Accelerated BMI gain & $3.1(0.8$ to 5.4$)$ & 0.009 & $1.5(-0.9$ to 3.9$)$ & 0.215 & $-1.3(-2.7$ to 0.1$)$ & 0.069 & $-1.8(-6.5$ to 2.9$)$ & 0.453 \\
\hline Lower birth size - Slower BMI gain & $-2.7(-4.9$ to -0.4$)$ & 0.020 & $-1.9(-4.2$ to 0.4$)$ & 0.108 & $0.7(-0.7$ to 2.1$)$ & 0.307 & $-0.4(-5.0$ to 4.1$)$ & 0.846 \\
\hline
\end{tabular}

All models were adjusted for maternal age at pregnancy, pre-pregnancy BMI, history of allergy-related disease, educational level, smoking during pregnancy, and child's gestational age, duration of any breastfeeding and lower respiratory tract infections during the first year

Abbreviations: BMI: body mass index; $\mathrm{FEF}_{25-75}$, forced expiratory flow 25-75\%; $\mathrm{FEV}_{1}$ : Forced expiratory volume in 1 second; FVC: forced vital capacity; Coef: regression coefficient: $95 \% \mathrm{CI}$; $95 \%$ confidence interval 
Table S6. Adjusted associations of early childhood BMI trajectories with lung function at seven years - Excluding children from mothers who smoked during pregnancy

\begin{tabular}{|c|c|c|c|c|c|c|c|c|}
\hline \multirow[b]{2}{*}{ BMI trajectories } & \multicolumn{2}{|c|}{$\begin{array}{c}\text { Percent predicted } \\
\text { FVC }(\%)\end{array}$} & \multicolumn{2}{|c|}{$\begin{array}{c}\text { Percent predicted } \\
\text { FEV }_{1}(\%)\end{array}$} & \multicolumn{2}{|c|}{$\begin{array}{l}\text { Percent predicted } \\
\text { FEV }_{1} / \text { FVC }(\%)\end{array}$} & \multicolumn{2}{|c|}{$\begin{array}{l}\text { Percent predicted } \\
\text { FEF 25-75 }(\%)\end{array}$} \\
\hline & Coef $(95 \%$ CI $)$ & $p$-value & Coef $(95 \%$ CI $)$ & $p$-value & Coef $(95 \%$ CI $)$ & $p$-value & Coef $(95 \%$ CI $)$ & $p$-value \\
\hline $\mathrm{n}$ & 995 & & 995 & & 995 & & 993 & \\
\hline Average birth size - Slower BMI gain & Reference & & Reference & & Reference & & Reference & \\
\hline Higher birth size - Accelerated BMI gain & $2.7(0.2$ to 5.3$)$ & 0.036 & $1.0(-1.6$ to 3.6$)$ & 0.448 & $-1.5(-3.0$ to 0.1$)$ & 0.064 & $-3.0(-8.1$ to 2.1$)$ & 0.247 \\
\hline Higher birth size - Slower BMI gain & $0.6(-1.2$ to 2.5$)$ & 0.511 & $0.9(-1.0$ to 2.8$)$ & 0.352 & $0.2(-0.9$ to 1.4$)$ & 0.683 & $0.8(-2.9$ to 4.5$)$ & 0.664 \\
\hline Lower birth size - Accelerated BMI gain & $2.4(-0.1$ to 5.0$)$ & 0.064 & $1.6(-1.0$ to 4.2$)$ & 0.228 & $-0.7(-2.2$ to 0.9$)$ & 0.402 & $-0.4(-5.4$ to 4.7$)$ & 0.886 \\
\hline Lower birth size - Slower BMI gain & $-2.8(-5.1$ to -0.4$)$ & 0.020 & $-1.4(-3.8$ to 0.9$)$ & 0.236 & $1.2(-0.2$ to 2.6$)$ & 0.086 & $1.2(-3.4$ to 5.8$)$ & 0.615 \\
\hline
\end{tabular}

All models were adjusted for maternal age at pregnancy, pre-pregnancy BMI, history of allergy-related disease, educational level, smoking during pregnancy, and child's gestational age, duration of any breastfeeding and lower respiratory tract infections during the first year

Abbreviations: BMI: body mass index; $\mathrm{FEF}_{25-75}$, forced expiratory flow 25-75\%; FEV 1 : Forced expiratory volume in 1 second; FVC: forced vital capacity; Coef: regression coefficient: $95 \% \mathrm{CI} ; 95 \%$ confidence interval 
Table S7. Adjusted associations of early childhood BMI trajectories with lung function at seven years - Excluding children with extreme lung function values $(<\mathbf{p 1} \&>$ p99)

\begin{tabular}{|c|c|c|c|c|c|c|c|c|}
\hline \multirow[b]{2}{*}{ BMI trajectories } & \multicolumn{2}{|c|}{$\begin{array}{c}\text { Percent predicted } \\
\text { FVC }(\%)\end{array}$} & \multicolumn{2}{|c|}{$\begin{array}{c}\text { Percent predicted } \\
\text { FEV }_{1}(\%)\end{array}$} & \multicolumn{2}{|c|}{$\begin{array}{l}\text { Percent predicted } \\
\text { FEV } 1 \text { FVC }(\%)\end{array}$} & \multicolumn{2}{|c|}{$\begin{array}{l}\text { Percent predicted } \\
\text { FEF } 25-75(\%)\end{array}$} \\
\hline & Coef $(95 \%$ CI $)$ & $p$-value & Coef $(95 \%$ CI $)$ & $p$-value & Coef $(95 \%$ CI $)$ & $p$-value & Coef $(95 \%$ CI $)$ & $p$-value \\
\hline $\mathrm{n}$ & 1,172 & & 1,171 & & 1,174 & & 1,172 & \\
\hline Average birth size - Slower BMI gain & Reference & & Reference & & Reference & & Reference & \\
\hline Higher birth size - Accelerated BMI gain & $2.7(0.6$ to 4.8$)$ & 0.013 & $1.3(-0.9$ to 3.4$)$ & 0.247 & $-0.8(-2.1$ to 0.5$)$ & 0.230 & $-0.9(-5.3$ to 3.4$)$ & 0.672 \\
\hline Higher birth size - Slower BMI gain & $0.2(-1.4$ to 1.7$)$ & 0.825 & $0.8(-0.7$ to 2.4$)$ & 0.293 & $0.6(-0.4$ to 1.5$)$ & 0.218 & $1.0(-2.2$ to 4.2$)$ & 0.534 \\
\hline Lower birth size - Accelerated BMI gain & $2.7(0.6$ to 4.8$)$ & 0.011 & $1.6(-0.5$ to 3.7$)$ & 0.136 & $-0.9(-2.2$ to 0.4$)$ & 0.157 & $-0.3(-4.6$ to 4.0$)$ & 0.889 \\
\hline Lower birth size - Slower BMI gain & $-2.8(-4.8$ to -0.8$)$ & 0.007 & $-1.6(-3.6$ to 0.4$)$ & 0.107 & $1.3(0.1$ to 2.6$)$ & 0.033 & $1.0(-3.1$ to 5.1$)$ & 0.637 \\
\hline
\end{tabular}

All models were adjusted for maternal age at pregnancy, pre-pregnancy BMI, history of allergy-related disease, educational level, smoking during pregnancy, and child's gestational age, duration of any breastfeeding and lower respiratory tract infections during the first year

Abbreviations: BMI: body mass index; FEF $25-75$, forced expiratory flow 25-75\%; FEV 1 : Forced expiratory volume in 1 second; FVC: forced vital capacity; Coef: regression coefficient: $95 \% \mathrm{CI} ; 95 \%$ confidence intervals 
Table S8. Adjusted associations of early childhood BMI trajectories with lung function at seven years - Excluding preterm children

\begin{tabular}{|c|c|c|c|c|c|c|c|c|c|}
\hline \multirow[b]{2}{*}{ BMI trajectories } & & \multicolumn{2}{|c|}{$\begin{array}{c}\text { Percent predicted } \\
\text { FVC }(\%)\end{array}$} & \multicolumn{2}{|c|}{$\begin{array}{c}\text { Percent predicted } \\
\text { FEV }_{1}(\%)\end{array}$} & \multicolumn{2}{|c|}{$\begin{array}{l}\text { Percent predicted } \\
\text { FEV } 1 / \text { FVC }(\%)\end{array}$} & \multicolumn{2}{|c|}{$\begin{array}{l}\text { Percent predicted } \\
\text { FEF 25-75 }(\%)\end{array}$} \\
\hline & & Coef $(95 \%$ CI $)$ & $p$-value & Coef $(95 \%$ CI $)$ & $p$-value & Coef $(95 \% \mathrm{CI})$ & $p$-value & Coef $(95 \%$ CI $)$ & $p$-value \\
\hline & $\mathrm{n}$ & 1,151 & & 1,151 & & 1,151 & & 1,149 & \\
\hline Average birth size - Slower BMI gain & & Reference & & Reference & & Reference & & Reference & \\
\hline Higher birth size - Accelerated BMI gain & & $2.8(0.5$ to 5.1$)$ & 0.015 & $1.1(-1.2$ to 3.5$)$ & 0.335 & $-1.4(-2.8$ to 0.0$)$ & 0.046 & $-2.8(-7.4$ to 1.7$)$ & 0.222 \\
\hline Higher birth size - Slower BMI gain & & $0.6(-1.1$ to 2.3$)$ & 0.495 & $1.2(-0.5$ to 2.9$)$ & 0.181 & $0.5(-0.5$ to 1.6$)$ & 0.315 & $2.1(-1.3$ to 5.4$)$ & 0.235 \\
\hline Lower birth size - Accelerated BMI gain & & $2.8(0.5$ to 5.1$)$ & 0.017 & $1.4(-1.0$ to 3.7$)$ & 0.257 & $-1.2(-2.6$ to 0.2$)$ & 0.103 & $-1.4(-6.0$ to 3.2$)$ & 0.546 \\
\hline Lower birth size - Slower BMI gain & & $-3.0(-5.2$ to -0.8$)$ & 0.008 & $-1.6(-3.9$ to 0.6$)$ & 0.161 & $1.3(-0.1$ to 2.6$)$ & 0.064 & $1.2(-3.2$ to 5.7$)$ & 0.581 \\
\hline
\end{tabular}

All models were adjusted for maternal age at pregnancy, pre-pregnancy BMI, history of allergy-related disease, educational level, smoking during pregnancy, and child's gestational age, duration of any breastfeeding and lower respiratory tract infections during the first year

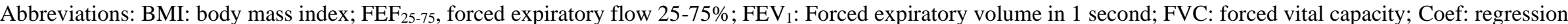
coefficient: $95 \% \mathrm{CI} ; 95 \%$ confidence interval 
Table S9. Adjusted associations of early childhood BMI trajectories with lung function at seven years - Restricting models to children with at least two acceptable manoeuvres reproducible within $150 \mathrm{~mL}$

\begin{tabular}{|c|c|c|c|c|c|c|c|c|}
\hline \multirow[b]{2}{*}{ BMI trajectories } & \multicolumn{2}{|c|}{$\begin{array}{c}\text { Percent predicted } \\
\text { FVC }(\%)\end{array}$} & \multicolumn{2}{|c|}{$\begin{array}{c}\text { Percent predicted } \\
\operatorname{FEV}_{1}(\%)\end{array}$} & \multicolumn{2}{|c|}{$\begin{array}{l}\text { Percent predicted } \\
\text { FEV }_{1} / \text { FVC }(\%)\end{array}$} & \multicolumn{2}{|c|}{$\begin{array}{c}\text { Percent predicted } \\
\text { FEF }_{25-75}(\%)\end{array}$} \\
\hline & Coef $(95 \%$ CI $)$ & $p$-value & Coef $(95 \%$ CI $)$ & $p$-value & Coef $(95 \%$ CI $)$ & $p$-value & Coef $(95 \%$ CI $)$ & $p$-value \\
\hline & 939 & & 939 & & 939 & & 939 & \\
\hline Average birth size - Slower BMI gain & Reference & & Reference & & Reference & & Reference & \\
\hline Higher birth size - Accelerated BMI gain & $4.9(2.4$ to 7.4$)$ & $<0.001$ & $2.7(0.2$ to 5.2$)$ & 0.033 & $-1.9(-3.4$ to -0.4$)$ & 0.014 & $-2.4(-7.4$ to 2.6$)$ & 0.354 \\
\hline Higher birth size - Slower BMI gain & $0.0(-1.8$ to 1.8$)$ & 0.994 & $0.2(-1.6$ to 2.0$)$ & 0.809 & $0.2(-0.9$ to 1.3$)$ & 0.711 & $0.7(-2.9$ to 4.2$)$ & 0.701 \\
\hline Lower birth size - Accelerated BMI gain & $2.4(0.0$ to 4.8$)$ & 0.046 & $0.9(-1.5$ to 3.3$)$ & 0.453 & $-1.4(-2.8$ to 0.1$)$ & 0.062 & $-2.6(-7.4$ to 2.2$)$ & 0.280 \\
\hline Lower birth size - Slower BMI gain & $-2.6(-4.9$ to -0.3$)$ & 0.025 & $-1.7(-3.9$ to 0.6$)$ & 0.154 & $0.9(-0.5$ to 2.2$)$ & 0.210 & $0.0(-4.6$ to 4.6$)$ & 0.997 \\
\hline
\end{tabular}

All models were adjusted for maternal age at pregnancy, pre-pregnancy BMI, history of allergy-related disease, educational level, smoking during pregnancy, and child's gestational age, duration of any breastfeeding and lower respiratory tract infections during the first year

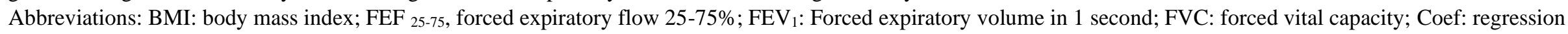
coefficient: $95 \% \mathrm{CI}$; $95 \%$ confidence interval 